\title{
THE CHALLENGE OF TERMINOGRAPHIC GAPS IN TRANSLATION: A TEXT-BASED APPROACH PUT TO PRACTICE
}

\author{
ABBAS MEHRPOOYA \\ University of Isfahan \\ abbas.mehrpooya@gmail.com
}

\section{AHMAD MOINZADEH (CORRESPONDING AUTHOR)}

University of Isfahan

moin@fgn.ui.ac.ir

\author{
AZIZOLLAH DABAGHI \\ University of Isfahan \\ azizollahd@hotmail.com
}

\begin{abstract}
The issue of terminographic gaps in specialized discourses has always concerned the researchers and readers alike. However, due to the interlingual nature of such a technical issue, the need for interdisciplinary collaboration between translation and terminography seems to be in prospect. For such a reciprocation scheme to come into practical effect, the present study has aimed to conduct a translational-terminographic concerto by putting a specialized English text to the test of Persian translation. This has been done to answer the question if a translator is required to provide for any terminological gap once all attempts at finding the corresponding terminological items have failed. In this pursuit, certain workable criteria for terminographic proposition via translation have been discussed. As such, the practical phase of this study concerns itself with addressing the issue of Persian terminological gaps in a language-related metadiscoursal field and consequently detecting the problem zones of non-equivalence in a specialised text carefully selected for translation. Ultimately, a list of Persian terminological items constructed on the basis of the proposed translational-cum-terminographical scheme is compiled to address the identified terminological gaps in the target metadiscourse under study.
\end{abstract}

Keywords: Specialized discourse, technical term, terminological gap, terminography, translation

\section{Introduction}

Special discourses are perceived to cross-lingually suffer from the problem of a lack of one-to-one correspondence with regard to their specialized terminology. This problem turns to be more acute in scientific discourses where a higher load of technical items makes cross-discoursal communication considerably more 
demanding. Such a dearth in terminological equivalence has led to a belief in the non-universality of technical language, what is rephrased by Montgomery (2010: 303) to be a condition where 'there is no one-to-one correspondence among different tongues when they express scientific information'. The field of Persian scientific discourses is no exception in this regard, that's why an exclusive emphasis has more frequently been laid on the necessity of doing terminographic work by both official and unofficial bodies. Ironically enough, such a persistent emphasis exclusively concerns the field of language-related scientific discourses and the need for giving more specialized dimensions to the terminological work in this area. In what follows, yet, we first go through a brief review of the dominant trend of scientific attitudes towards terminographic work in the field of sciencerelated Persian discourses.

\section{Scientific 'word-selection': a persian outlook}

As a matter of research findings, the field of Persian scientific terminology reflects a critical need for cross-lingual terminographic work. Therefore, efforts have been put by individual scholars and official institutions in trying to make up for such terminological demands. Sadeghi (1991) appears to recognize that the efforts made by the official word formation assemblies such as Farhangestaan [Iran's official language institution $]^{1}$ and the unofficial organizations and groups as well as specialists in various scientific fields have all prompted the Persian language to assume the responsibility of 'facing the modern civilization, sciences, and technology' (p. 12). The name of Farhangestan being identified with wordselection endeavour [apart from the fact that the proper terminology to be used here is term-selection rather than word-selection that is the translation of vaaj-e gozini in Persian], efforts are also being made to announce and highlight the identity-changing of such an 'endeavour' into becoming a science, after two decades of trial and error. In this regard, mention is also made of aiming to make the Persian language the language of science by resorting to out-sourcing as a suitable strategy to seek the cooperation of scientific and academic bodies in accomplishing the goal of 'word-selection' (Haddad-e Adel 2008).

In the same pursuit and from a more practical standpoint, reference can also be made to a technological attitude displayed towards the work of 'word-selection' as such and viewing the scientific discourses as the industrial sites of 'massive' word production (Mansuri, 2003). It is in the same pursuit, too, that Kaafi (1995), in a study that aims to provide a systematized set of rules for Persian wordselection, tries to draw scientific principles of lexical formation and selection out of studying a selection of 'words' proposed by the scientists of both past and present eras. Besides, seeing the work of word-selection as a knot-loosening or

Farhangestan: Cultural Institution of Persian Language and Literature's Council of Lexical Selection / Academy of Persian Language and Literature (APLL) 
problem-solving action and viewing 'rationalization' as the cornerstone based on which the problem can be solved, Nematzadeh (2000) provides a typology of 'rationals' for the job of word-selection. The individual $v s$ collective dichotomy is the primary classification she provides based on whether the job of 'wordselection' is done individually or collectively.

The traces of lexical selection in Persian can still further be sought among other scholars from other dialects of Iranian origin as well as other Persian-speaking nations outside Iran. Though the number of such studies is few, a case in point can be the short descriptive account provided by Yamin (2004) which simply points to and typifies the still sporadic and inharmonious attempts at 'word-selection' desultorily carried out here and there in Afghanistan. It is due to this state of desultoriness that Yamin calls for the necessity of establishing an official body to undertake and systematize the 'word-selection' work; thus settling such existing discordancy through the cooperation provided by Iran's Farhangestan of Persian Language and Literature.

The critical attitudes to addressing the so-called issue of 'word-selection' in Persian, typically referred to above, are remarkable in their own right. However, such concerted efforts have been carried out only through the magnifying glass of linguists, Persian literature academicians, and lexicographers. Ironically enough, what are lacking in this field are the translationally-offered contributions and the alternative perspective the translation and the current generation of educated translation practitioners can bring to this field, both in theory and practice. What's more, such a lacking in Persian terminographic work seems to notably exist in such specific language-related discourses as the field of 'lexical databases'. That's why in the practical phase of this study the terminological gaps of a metadiscoursal text related to lexical databases has been brought under investigation through translation; what is to be tackled with more elaborately by adopting a text-based translational approach.

\section{Research questions}

Viewing the issue of Persian terminological proposition as a compelling need, this study has addressed the vital necessity for adopting a translational approach towards the issue of terminographical work. As such, the present article in its theoretical phase has planned to investigate the frequently-ignored topic of the reciprocity of translational and terminographical work in the field of Persian discourses. In order for the theoretical assumptions of this study to gain more of an interdisciplinary momentum, an initial discussion on certain pertinent conceptions from both fields of translation and terminography is initiated. To further such a theoretical position towards assuming a practical dimension, an experiential scheme has been planned on the basis of a case study involving the translation of a carefully-selected piece of discourse originally written in English. It should be pinpointed that the choice of the meta-discursive text under study for 
translation into Persian has been carried out based on the judgmental attitudes of certain Persian subject-field experts. Apart from the theoretical concerns, there is also a two-fold reason why a meta-text has been selected for translation here. Firstly, in trying to identify and in favour of verifying the inherent terminological needs of a metadiscoursal text of the type: This will have practical bearings with regard to what criteria are needed for terminographic proposition by a translator. Secondly, in attempting to draw on the rich relevant terminological content such a metatext will appear to hold within itself with regard to the its related terminological field: This will attest the hypothesis of the practicality of adopting a text-based translational approach to terminographic proposition.

As such, and within a practical sphere, taking into consideration the case of interlingual terminographic proposition, the main concern of this study is not what the consulted terminographic sources provide in terms of equivalent-finding for discoursal translation, but what they practically do NOT. In theoretical terms, therefore, the main question the present paper tries to answer will be: Is there any need for a translator to provide for the TL terminological gaps during the translation of a specialized text? The answer to this question is provided during and after the completion of the translation work. Accordingly, if the answer to this first question is positive, a related question will be to what part-of-the-speech category/categories the probable terminological gaps belong. In addition, a further theoretical bone of contention will concern the question of what pertinent translational-cum-terminological criteria or requirements will matter most with regard to promoting the terminographical work for the technical discourse(s). Ultimately, the major goal the presnt study is going to accomplish in its last practical phase is to provide for the terminological gaps detected via translating the carefully-selected piece of metatext. On that account, the ultimate list of the proposed Persian terminology is planned to be proposed to fill the existing terminological gaps that are left un-identified and un-treated in the related metadicourse under study. As such, it must be said that any attempt at trying to resolve the above-cited hypothetical questions will seek to confirm the assumption that the more specialized a text, the bigger the challenge it will constitute in terms of providing for the terminological shortfalls in the target discourse.

\section{Procedure}

After selecting the metatext to be worked on through experts' judgment, the overall number of lexical items existing in the text was determined. To be able to calculate and compare the related lexicological and terminological frequency scores, the number of terminological items existing in the text under study have also been quantified by three experts. The quantification of the terminological items was carried out on the basis of the technical definition of term/terminology provided by Cabré (1999). The process of quantifying the terminological gaps was conducted through putting the text under study to the test of translation. During 
the translation process, the terminographic consultations were sought in a range of primary and secondary sources. The consulted sources have included the most pertinent bilingual dictionaries as well as the subject-field experts. The consultation process as such has placed any of such sources at the prime position of a reference point in the process of ad-hoc construction of the terminological 'comparables', to underline Ricoeur's (2006) translational formula of 'constructing comparable'. It was only after the completion of the translational process that the terminological gaps existing in the metadiscourse under study were identified. However, having not arrived at any working equivalent for the terminological gaps detected, the study entered into its next-to-last practical stage, that is the proposition of the target terminology on the basis of a translationallysupported terminographically-oriented approach to be discussed later in this article. As the last procedural step, the terminographic items constructed and proposed for the lacking terminology were put together to make out a glossary of proposed items to be communicated to the pertinent bodies. This ultimate stage will accredit the last stage in Cabré's ad-hoc search process referred to later in the section 6 of this article.

As such the implemented procedure has turned to bring together major related formula from translation, i.e. Ricoeur's 'constructing comparables', and termniography, i.e. Cabré's 'ad-hoc search process', while having an eye to certain issues contributing to the construction of corresponding terminology, i.e. morphological correspondence and technical suggestivity, to be explained further in this article.

\subsection{Procedural justifications}

\section{Meta-discourse: A Translational Medium}

From the translational-cum-terminographical standpoint foregrounded in this study, the construction of the corresponding terminographic items for the target discourse will follow the translation of a specialized text or piece of discourse. As such, the translation of the source text is the key to the existence of certain terminographic gaps in the target discourse. Consequently, the text to be translated is the very site wherein the terminological gaps in need of terminological innovation are identified and verified in the receptor discourse. Thus, for a practical give-and-take to be ensured between the translation and terminography, the mediatory role of the source text to be translated should be taken into account.

Seeking recourse to the text/discourse as the subdomain of the context, assertion should be made that the translator in carrying out his/her translational role does not move from the word to the sentence, to the text, but conversely: absorbing the wider dimensions of the spirit of a discourse type, the translator descends from the whole text down to the sentence towards the word (see Ricoeur 2006: 27). In this manner, the selected source text appears to avail the practicing 
translator with the contextualized concepts for which the target terminological items are to be provided. As such, the translation-oriented lexicological/terminological innovations can be viewed as examples of 'neosemantic forms', to use Augustyn's (2013) terminology, that are guided by and introduced in context. Therefore, viewed from a semantico-syntactic point of view, the idea of translational-cum-terminographic work can as well bear special relevance to Augustyn's emphasis on context-prone terminography.

Moreover, from a terminological point of view, what rises to give a fresh momentum to the translational prominence of 'text' as such is the emphatic terminographic salience given to 'terms' as 'discourse units' by Cabré (2010). Wherever there is a dearth of discourse on a subject area, she maintains, then the translated text $(s)$ can be used as terminological source(s). Such a reciprocal relationship between translation and terminography with the centrality of a text as an interactive medium can be outlined as follows:

\section{Discourse-oriented}

translation

\section{A Text in}

Translation

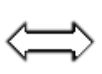

Terminographic

work

Figure 1. The reciprocal relationship between discourse-oriented translation and terminographic work.

It was on this ground, therefore, that a metadiscoursal text, that is Fellbaum's (1998) basic paper on the key aspects of WordNet lexical database(s) - itself selected through experts' judgment - was put to the test of translation. Thus, the technical text at hand which counted to 4869 words was hypothesized to pose certain equivalence problems in translation due to its containing of a heavy load of technical content, i.e. specialized terminology; hence providing the translationbased indication as to where the terminological innovations need to be made.

\subsection{Text as supplier of terminological gaps}

Referring to 'term' as a designatory lexical item, Cabré (1999: 35) describes a term as a unit with 'a set of systematic linguistic characteristics' which is used in a special domain, as compared with a word which has the same linguistic characteristics except that it refers to an element in reality. In this regard, it can be concluded that a 'term' is a lexical item which is used in a specialized discourse just to give a designation/name to a phenomenon or a special category in a special subfield. In terms of the word-term dichotomy referred to above and in reference to Cabré's (1999) schematic mapping wherein a language is shown to embody the 
narrower domains of specialized languages, the coverage domain of a specialized discourse can be illustrated more vividly. It must be said that each text as a subset of a specialized discourse domain shares features with other texts, while differing with them in certain other features. Obviously, terminological contents are themselves the points which constitute a portion of such shared and differing features. This idea has been illustrated more clearly in Figure 2, what illustrates the coverage-domain of a specialized discourse, itself entailing the sub-domains of certain intersecting related texts.

In translation of a specialized text, it is possible that any attempt at providing the corresponding target item(s) for certain terminological item(s) - via consulting the related specialized sources - may fail. Consequently, such presumed terminological gaps are those that are to be filled by the translator by resorting to a translationally-supported terminography-oriented approach. To illustrate the coverage domain of a specialized discourse domain and its related texts as well as the probable terminological gaps, this study proposes the Figure 2, below.

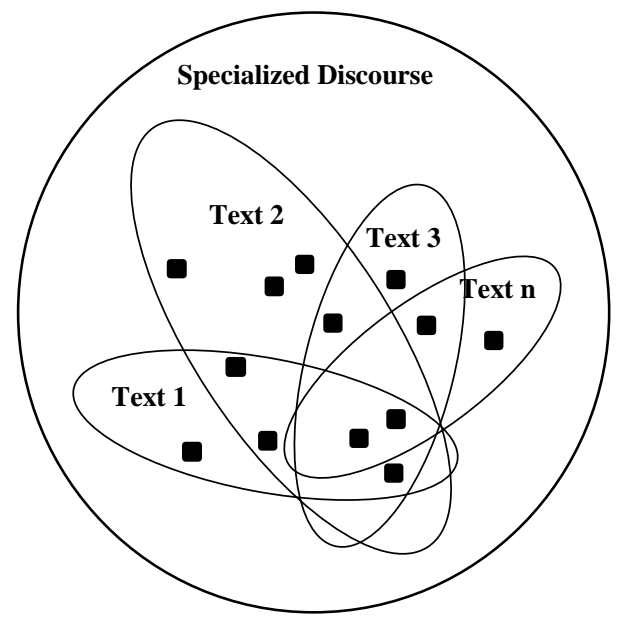

Figure 2. Coverage domain of a Specialized discourse domain and the related texts with terminological gaps

In a broader sense, if it can be pre-assumed that there may probably exist some terminological gaps in a specialized discourse domain, it can be concluded that certain number of such slots will expose themselves in the translation of a related text - illustrated by black squares in Figure 2. Therefore, it is to be said that any translated text is one text among the many in a specialized discourse domain which might probably make its own contribution to its related discursive domain. 


\section{Dealing with terminographic gaps}

\subsection{Ad-hoc construction via ad-hoc search}

In trying to address the translational challenge of terminological gaps, the translational trial to be conducted not only is a means to investigate the predicted results for the present study, but also is to offer practical bearings for certain translational and terminographical theories. Remarkable among such benefiting viewpoints, one can first and foremost point to the ideal position taken by Ricoeur who voices fervent hope in favor of the fact that it is upon the translation and the translator to provide for the comparable equivalence. Cherishing a long tradition of pro-equivalence endeavour, Ricoeur $(2006: 18,22)$ shows a promising avenue in prospect where he maintains that although the destiny of translation appears to be 'inscribed in the long litany of 'despite everything", the 'equivalence' is still to be sought for. Further in his discussion on translation, Ricoeur (2006) proposes the theme of constructing the comparables as a formula to be applied to the translation of a text or a piece of discourse in an attempt to solve 'the mystery of equivalence by constructing it'. Straightforwardly showing such a prospective path, he thus rephrases his constructive notion as 'the production of equivalence through translation' (p. 35). Looking at the findings of this study in the mirror of Ricoeur's prospective conception, it can be asserted that the problem of terminographical gaps in specialized translation far from being an insurmountable obstacle can usher the theoreticians and practitioners alike into believing in the necessity of terminographic work in the process of translation where the need arises.

From a terminographic point of view, however, the need for carrying out such a compensatory term-providing plan, as previously stated, is justified by Cabré's introduction of the strategic notion of ad-hoc search. The situation in which an ad-hoc search is required to be done is identified by Cabré (1999: 152) as follows:

By ad-hoc search, as opposed to systematic search, we mean work on an isolated term or a limited set of terms in a single special subject. This approach to work is usually the result of a query that a user addresses to a terminological service. (p. 152)

It is in dealing with the same self-explanatory, yet practically undervalued, relevance [and viewing terminology as a more specialized sub-area of lexical designation] that Cabré (2010) stipulates that terminology is considered as a problem-solving tool in the hand of a user, here a translator. In Cabré's view, also, documents in translation can be viewed as sources from which terms are extracted, wherever no original texts on a special subject exists in the target language. This confirms the procedural scheme proposed by the present study based on which the translated text is viewed as the specialized site wherein the terminological gaps in the target discourse are located. 
As a final point of procedural justification, it can further be pinpointed that the tangible theoretical link which tends to collect the two disciplines is provided by those scholars who emphasize the necessity for the co-operation between the translators and lexicographers/terminographers as well as the prospective gotogetherness of the findings of translation and lexicography/terminography as two distinct, yet related, disciplines. The confirmatory ground for such a pragmatic compromise to occur is to be sought in the assertions made by such scholars as Hartmann (2007) who view the bilingual lexicography as a concerted effort made as the result of the close collaboration between acts of translating and dictionarymaking. In this view, Hartman sees bilingual dictionaries as 'a repository of the collective equations established by generations of "translating lexicographers", (2007: 18). In the same vein, mention can be made of the emphasis placed by Burkhanov (1998) on the recurring notion of 'translation equivalent', a key notion which appears to fairly straddle with both the translational and lexicographic/terminographic ends. In this regard, the notion of 'translation equivalent' appears to denote 'a category of primary importance for both translation theory and translation lexicography [as well as translation terminography as this study aims to investigate]' (p. 249). For that reason and by implication, viewing the issue of Persian terminological proposition as such, this article has been an attempt to bring closer the prospective notions of constructing comparables and ad-hoc terminolographic work in the light of viewing the translation and terminography as two reciprocal endeavours.

\subsection{Providing for terminographic gaps}

In trying to deal with the challenge of Persian terminographic gaps and providing for the target terminology, the procedural formula to adopt has been Cabré's (1999) proposed ad-hoc search plan. According to Cabré's formula, in case where the problem of non-existence of some term or confusion resulting from equivalence disparity occurs, the translator should follow the procedural method below:

- analyze the case

- consult the material

- consult subject experts, if necessary

- make a proposal

- provide a provisional response

- $\quad$ communicate the proposal to the pertinent bodies. (1999: 157)

Accordingly, in the last practical phase of the present study and in trying to provide the terminographic proposals for the translated text at hand, the above procedure has been followed. Below, we go through the details of applying the translationally-sustained terminographically-oriented process to the case at hand, that is the technical metatext on the key aspects of WordNet lexical database(s). In this stage, this study aims to identify and verify the existence of terminological 
equivalence gaps between English, the ST language, and Persian, the TT language. Needless to say, the detected terminological gaps are suggestive of the existence of the same terminological gaps in the Persian metadiscourse of lexical database(s) that need to be made up for in the final stage of terminographic construction.

\section{The case study}

\section{Metadiscourse on lexical databases}

Parting away from the theoretical issues, we now look into the explicit details of terminological gaps in the metadiscourse of Persian lexical database(s). As discussed above, a metadiscoursal text, i.e. Fellbaum's (1998) basic paper on the key aspects of WordNet lexical database(s), was selected for translation in the first practical stage of this study. Practically, the aim of detecting the terminological gaps in the metadicourse of Persian lexical databases was realized through translating the selected text. In so doing, as a procedural prelude, the technical definition of term/terminology provided by Cabré (1999) was firstly used to differentiate term(s), i.e. technical items(s), from general word(s) existing in the text. The concepts of 'word' and 'term' are technically differentiated and defined by Cabré (1999):

A word is a unit described by a set of systematic linguistic characteristics and has the property of referring to an element in reality. A term is a unit with similar linguistic characteristics used in a special domain. From this standpoint, a word of a special subject field would be a term (p. 35).

On this account, it was through adopting a translational approach towards the metatext under study and consequently consulting the equivalent-providing sources mentioned above that the terminological gaps in the metadiscourse under study were detected, their category identified, and their quantity determined. The sources consulted were Dictionary of Linguistics and Related Sciences (1992), Descriptive Dictionary of Semantics (2006), and the subject-field expert(s). It was hypothesized that the results of this stage would provide the necessary materials for carrying out the subsequent phase of constructing the comparable terminography. This is the core of the practical phase of the present study, yet the next section will bring together and explain some related issues in 'terminographic construction' and highlight certain criteria of relevance in this regard.

Following the procedural requirement as explained above, the overall terminology existing in the metadiscourse under study were recognized and quantified on the basis of experts' judgement, three experts, while taking into account Cabré's provided definition. The average list of terminological enumeration mounted to 297 items. In the final rendition, the results of ad-hoc 
search for the terminology lacking in the consulted sources mounted to 23 items out of the total 297 terms in the text under translation. The twenty-three detected items were considered as points of terminographical gaps (Table 1).

Table 1. Total counts for word, term, and terminological gaps

\begin{tabular}{|l|l|}
\hline ITEM & Total Count \\
\hline Words & 4859 \\
\hline Terms & 297 \\
\hline Terminological Gaps & 23 \\
\hline
\end{tabular}

In what follows, the graphic description of the results of the translational approach to terminographic proposition for the discourse of Persian lexical database(s) is provided. It is to be restated that in the process of translationally-sustained terminographic work, certain terms applied in the opted-for text are considered as the source terms, while the equivalents proposed based on them are to be known as target terms. Accepting that the terms are but specialized lexical items, the overall percentage values based on the frequency facts determined for the specialized $v s$ unspecialized lexical items, as provided in Table 1, are shown in the Graph 1. It must be said that the specialized or terminological items counting to 297 in number are themselves a portion of the total count of the lexical items in the text. As shown in percentage terms, specialized terms make up a reasonable percentage of $6.1 \%$ within the overall percentage of lexical items included in the text under translation. However, it is in Graph 2, that the percentage of source terminology that are in want of corresponding TL terms are provided, what is mounting to 23 items in table 1.
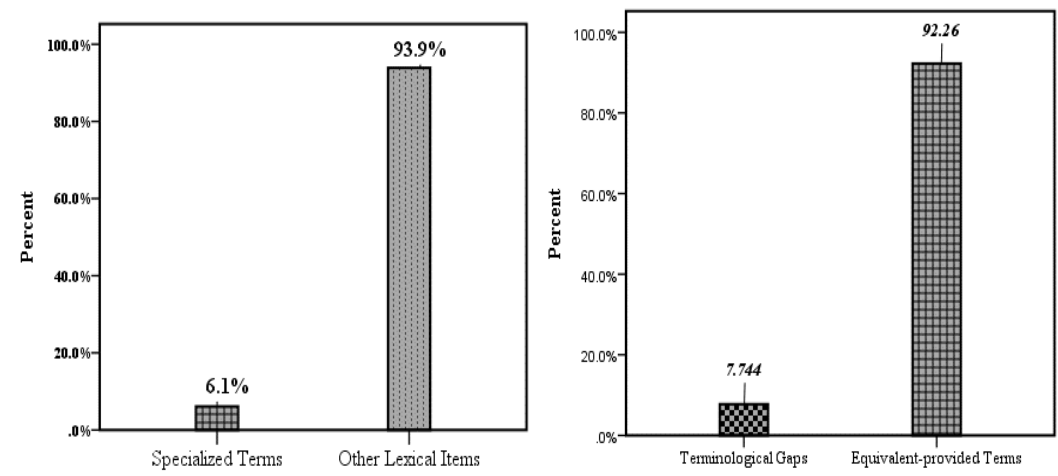

Graph 1 (Left). Overall percentage of terminological items within other lexical items Graph 2 (Right). Overall percentage of terminological gaps vs terminological non-gaps

The percentage value for the terminological gaps, as it can be seen, is 7.744. It is to be mentioned that the terminology in need of terminographic proposition, or in translational sense the terminological gaps, form a portion of the overall 
specialized items included in the source text. A more vivid picture of the overall percentage of terminographic gaps detected is displayed in the Graph 3 - the slice cut out - where the remaining section of the pie-chart graph covers the terminological items for which corresponding TL terms have been provided in the related sources.

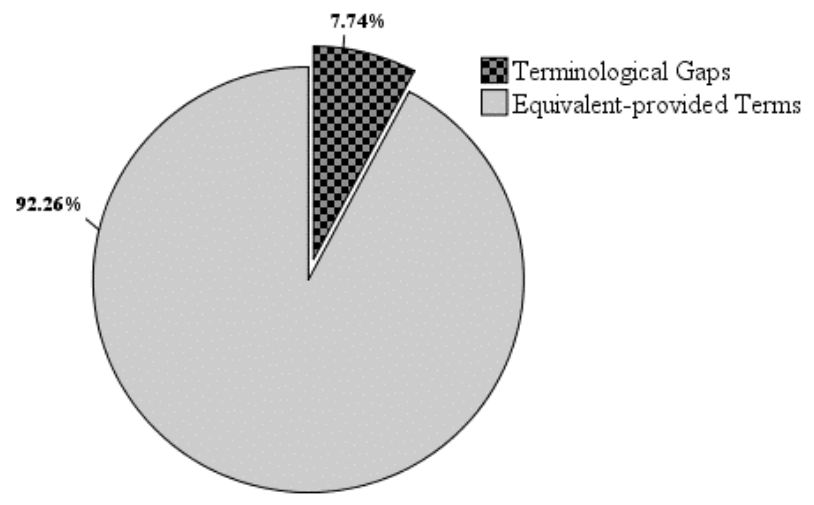

Graph 3. Overall percentage of terminological gaps within other lexical items (Pie-chart graph)

In this regard, mention can be made of the terminological gaps for such items as synset/synonym set, concordance, superordinate, tagging, meronymy, troponymy, manner-of relation, barbell model, lexical entailment, middle alternation ... . What these graphs logically imply is that in translating a specialized text, after every attempt at equivalent-finding, in and through the related specialized sources, has failed, such target terminological gaps are to be provided for. Practically, such a lacking state is to be compensated for via a translational scheme in which the work terminographic innovation is a locus of attention.

\subsection{Terminographic proposition: equivalence issues}

\section{'Morphological correspondence'}

The issue of equivalence has proved to be a knotty matter which has afflicted the debates on translation for so long. The extent of such controversy over lexical equivalence is so wide that Hermans, as referred to by Schäffner (2004:1255), appears to foreground the issue of in-equivalence or 'difference' over equivalence in translational ventures. In translational terms, a text-wise attitude towards terminographical provision adopted in this study can particularly be seen in terms of the formal correspondence vs textual equivalence dichotomy proposed by Catford. According to Catford (1965: 27), the formal-correspondence conception of equivalence refers to 'any TL category (unit, class, structure, element of 
structure, etc.) which can be said to occupy, as nearly as possible, the "same" place in the "economy" of the TL as the given SL category occupies in the SL'. This differs from the textual-equivalence conception which concerns any portion of TL text as the equivalent of a given portion of SL text. Based on the latter view, the equivalence perceived as such involves the relations which exist between specific ST-TT pairs with an eye to Saussure's parole, and not with languages compared and described as systems (Hatim and Munday 2004). However, the present approach, while giving the primacy to text as the semantic field wherein terms as discursive items appear, does not part from - and in fact foregrounds - the idea of formal correspondence from a morphological perspective. Regarding the fact that what we see as terms, and not words, in scientific discourse shows relatively less semantic variability across the different texts within a specialized field, this very idea of morphological correspondence finds a more justificatory ground. Viewed as such, the notion of terminological proposition based on morphological correspondence can be seen as a practical compromise to achieve fair consistency between the source term and target term to be proposed on the one hand, and the target term proposed as a common technical element to be applied by various target texts within a specialized discursive field on the other.

\section{'Technical suggestivity'}

In terminographical terms, this idea of formal consistency appears to be in essential accord with Cabré's (1999: 194) special emphasis on the discursive necessity for 'communication without ambiguity', a condition which requires of 'each designation to correspond to a single concept', while requiring of each concept to be designated only by 'a single term'. Placing stress on the semantic practicality of utilizing target morphological components similar to those used in the morphological make-up of the source-text items, it can be stated that each 'single term' in this sense can be seen as a 'telling' textual component worked in the grand structure of its related scientific discourse. This is to be followed by the notion of technical suggestivity in this study which places a due demand on any proposed target term to retain a proportionate technical sense for its associated discourse. It is nearly within the same perspective that Mehrpooya and Nowroozzadeh (2013: 406), looking at technical metaphors as the 'windows worked in the grand scientific edifice' of specialized discourse, remind us of the economic proposition such discursive components can provide the users with, what is sometimes expressible by perhaps paragraph-long chains of words. This also tallies with Johnson's (1992) concern over not to propose those terms from which the 'technical details' have been pushed away; what might lead to a 'mannered' use of jargon items that are mimetically utilized without being truly understood by their end-users.

Seen this way, the notions of 'morphological correpondence' and 'technical suggestivity' have been placed at the core of terminographic proposition in the sense discussed here in this study. Thus, it can be seen that a special emphasis 
falls upon the necessity of selecting as closest meaning-bearing morphological components as possible. Being placed in the structure of a proposed term, the relavant corresponding morpheme(s) might give the related end-users a subtle hint of what the proposed technical term, in its total morphological make-up, is to be suggestive of. As such, a morphological congruity with the structural make-up of any source item and its technical bearing(s) should be retained and wrought out within the target terminographic item as well; while taking into consideration the morphological possibilities of the target language.

Parting away from discussing the basic notions of morphological correspondence and technical suggestivity, both associated with the work of terminographic proposition, we now go through the list of the Persian terminology proposed for the metadiscourse of lexical databases.

\subsection{Target terminology constructed}

\section{Ultimate list to be proposed}

In fine, by virtue of adopting a translational approach towards a carefully-selected text, i.e. Fellbaum's paper on WordNet discourse, and drawing on the existing terminographic gaps in the translated text as well as the related Persian metadiscourse, a sample list of Persian terminographical proposals in the form of a glossary was proposed. Triggered by the direct relevance of the idea of constructing comparables proposed by Ricoeur (2006), it is further to be noted that in such proposing the target terminology, the above-discussed criteria, i.e. 'morphological correspondence' and 'technical suggestivity', have been applied in go-togetherness with Cabré's formula of ad-hoc search. As a last step, the ultimate list of the proposed Persian terminology to fill the detected terminological gaps related to the metadiscourse of Persian lexical database(s) is included here (In the table, 'G' stands for gloss; the morphemic-glosses translinearly correspond with the morphological order of proposed Persian terms):

Table 2. List of proposed terminology

\begin{tabular}{|c|c|c|c|c|c|}
\hline \multicolumn{2}{|c|}{ Terminology: Nouns } & \multicolumn{4}{|c|}{ Terminology: Nominal Phrases } \\
\hline $\begin{array}{c}\text { Source } \\
\text { term \& } \\
\text { page no. } \\
\text { in text } \\
\end{array}$ & $\begin{array}{c}\text { Target term } \\
\text { proposed }\end{array}$ & $\begin{array}{c}\text { Source } \\
\text { term \& } \\
\text { page no. } \\
\text { in text } \\
\end{array}$ & $\begin{array}{c}\text { Target perm } \\
\text { proposed }\end{array}$ & $\begin{array}{c}\text { Source } \\
\text { term \& } \\
\text { page no. in } \\
\text { text } \\
\end{array}$ & $\begin{array}{c}\text { Target term } \\
\text { Proposed }\end{array}$ \\
\hline $\begin{array}{l}\text { 1. } \\
\text { Synset } \\
\text { (p. 210) }\end{array}$ & 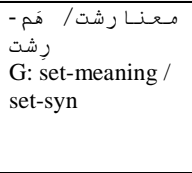 & $\begin{array}{l}\text { 1. } \\
\text { Synonym set } \\
\text { (p. 210) }\end{array}$ & 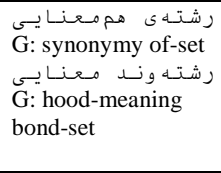 & $\begin{array}{l}\text { Middle } \\
\text { alternation } \\
\text { (p. 215) }\end{array}$ & 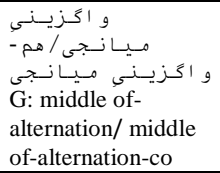 \\
\hline $\begin{array}{l}\text { 2. } \\
\text { Hyponym(s) } \\
\text { (p. 210) }\end{array}$ & 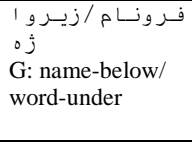 & $\begin{array}{l}\mathbf{2 .} \\
\text { IS-A } \\
\text { relation } \\
\text { (p. 210) }\end{array}$ & 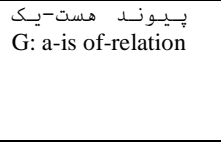 & $\begin{array}{l}12 . \\
\text { Hierar- } \\
\text { chical } \\
\text { structure } \\
\text { (p. 215) } \\
\end{array}$ & 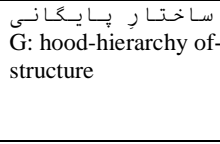 \\
\hline
\end{tabular}




\begin{tabular}{|c|c|c|c|c|c|}
\hline \multicolumn{2}{|c|}{ Terminology: Nouns } & \multicolumn{4}{|c|}{ Terminology: Nominal Phrases } \\
\hline $\begin{array}{c}\text { Source } \\
\text { term \& } \\
\text { page no. } \\
\text { in text }\end{array}$ & $\begin{array}{c}\text { Target term } \\
\text { proposed }\end{array}$ & $\begin{array}{c}\text { Source } \\
\text { term \& } \\
\text { page no. } \\
\text { in text }\end{array}$ & $\begin{array}{c}\text { Target perm } \\
\text { proposed }\end{array}$ & $\begin{array}{c}\text { Source } \\
\text { term \& } \\
\text { page no. in } \\
\text { text }\end{array}$ & $\begin{array}{c}\text { Target term } \\
\text { Proposed }\end{array}$ \\
\hline $\begin{array}{l}\text { 3. } \\
\text { Hyponymy } \\
\text { (p. 210) }\end{array}$ & 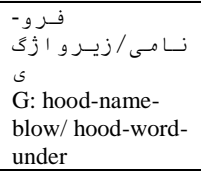 & $\begin{array}{l}\text { 3. } \\
\text { Part-whole } \\
\text { relation } \\
\text { (p. 210) }\end{array}$ & 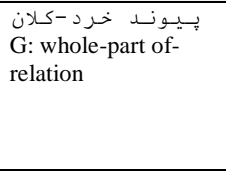 & $\begin{array}{l}13 . \\
\text { Semantic } \\
\text { concordance } \\
\text { (p. 217) }\end{array}$ & 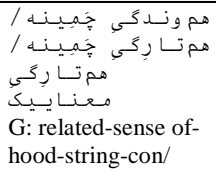 \\
\hline \multirow[t]{2}{*}{$\begin{array}{l}4 . \\
\text { Super- } \\
\text { ordinate } \\
\text { (p. 210) }\end{array}$} & \multirow[t]{2}{*}{ 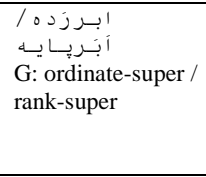 } & \multirow{2}{*}{$\begin{array}{l}4 . \\
\text { Super- } \\
\text { ordinate } \\
\text { relationship } \\
\text { (p. 210) }\end{array}$} & \multirow{2}{*}{ 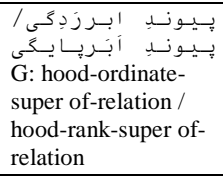 } & & $\begin{array}{l}\text { hood-sense of-hood- } \\
\text { cord-co/ hood- } \\
\text { meaning of-hood- } \\
\text { cord-co }\end{array}$ \\
\hline & & & & \multirow{7}{*}{\multicolumn{2}{|c|}{$\begin{array}{c}\text { [Note: Persian terminology are } \\
\text { proposed } \\
\text { by A. Mehrpooya] }\end{array}$}} \\
\hline $\begin{array}{l}\text { 5. } \\
\text { Merony-my } \\
\text { (p. 210) }\end{array}$ & 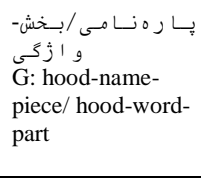 & $\begin{array}{l}\mathbf{5 .} \\
\text { Direct } \\
\text { antonymy } \\
\text { (p. 212) }\end{array}$ & 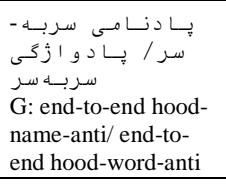 & & \\
\hline $\begin{array}{l}\text { 6. } \\
\text { Collocate* } \\
\text { "The term } \\
\text { collocate is } \\
\text { the basis for } \\
\text { proposing the } \\
\text { term } \\
\text { collocation } \\
\text { (p. } 210 \text { ) }\end{array}$ & $\begin{array}{l}\text { G: comer-co } \\
\text { (collocation: } \\
\text { (همآيخى) }\end{array}$ & $\begin{array}{l}6 . \\
\text { Manner-of } \\
\text { relation (p. } \\
213)\end{array}$ & 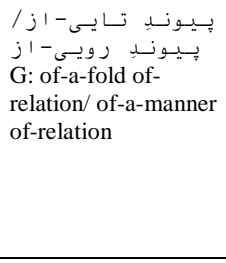 & & \\
\hline $\begin{array}{l}7 . \\
\text { Ambiguity } \\
\text { (pp. 211-12) }\end{array}$ & 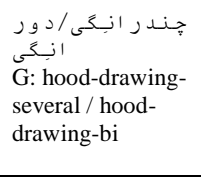 & $\begin{array}{l}7 . \\
\text { Barbell } \\
\text { model } \\
\text { (p. 212-13) }\end{array}$ & 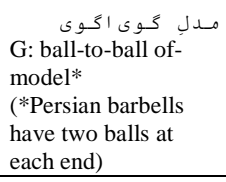 & & \\
\hline $\begin{array}{l}8 . \\
\text { Troponymy } \\
\text { (p. 213) }\end{array}$ & 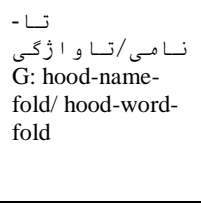 & $\begin{array}{l}8 . \\
\text { Lexical } \\
\text { entailment } \\
\text { (p. 214) }\end{array}$ & 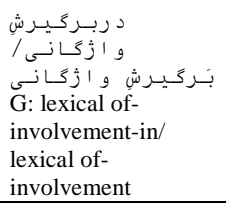 & & \\
\hline $\begin{array}{l}\text { 9. } \\
\text { Polysemy } \\
\text { (p. 214) }\end{array}$ & 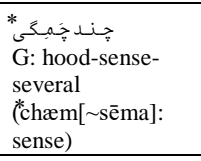 & $\begin{array}{l}9 . \\
\text { Backward } \\
\text { presuppositi } \\
\text { on } \\
\text { (p. 214) } \\
\end{array}$ & 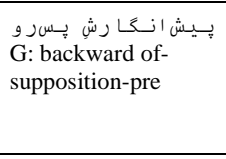 & & \\
\hline $\begin{array}{l}10 . \\
\text { Poly-sem(s) } \\
\text { (p. 214) }\end{array}$ & 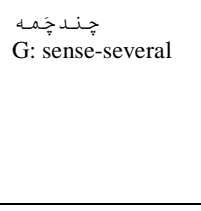 & $\begin{array}{l}10 . \\
\text { Unilateral } \\
\text { relation } \\
\text { (p. 214) }\end{array}$ & 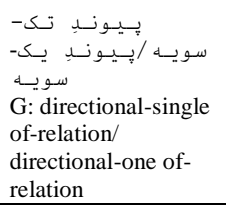 & & \\
\hline
\end{tabular}

\subsection{Implications and findings}

A practically significant finding of the present research relates to the need for assuming a terminographic side to technical translation where the ideal of providing the corresponding target item for the source item is in prospect. This 
point is attested by the results obtained from the initial practical stage of this study; that is the results related to the existence of a considerable number of terminolographical gaps/slots in the consulted sources and consequently the target metadiscourse under study. As a logical consequence, where the existence of certain terminographic gaps is detected and verified in the target specialized discourse, terminographic proposition seems to be an essential phase in the process of translating the specialized text or piece of discourse. Therefore, though at a micro-level of discourse, the results of the present research appear to view as vital the necessity for recognizing a terminographic side to translation. This in itself can be regarded to be one of the major practical implications the present research might turn to carry for the pertinent bodies.

What can be mentioned as a further finding of the present study is the fact that it is solely the terminographical gaps in the noun or nominal category which is observed to be of high frequency in translating the opted-for text. The high frequency of nominal terminographical gaps attests to the designatory nature of such terminological entities. In other words, this finding is suggestive of the terminological primacy of nominal form over other forms in such inequivalence prone discourses. This duly points to the fact that among the terminological units used in special fields, 'those of nominal category with referential and denominative value are the prototypical terms' (Cabré, 2010: 358). This might also be confirmed by the emphasis laid by Cabré (1999) on 'the priority of the concept over the designation' in the field of terminology as compared to lexicology where the reverse is the case. In this regard, Cabré asserts:

The aim of terminographers is to assign names to concepts; i.e. they move from the concept to the term (an onomasiological process). By contrast, lexicographers start with the word the dictionary entry - and characterize it functionally and semantically; i.e., they move from the word to the concept, precisely in the opposite direction (a semasiological process). (1999: 7-8)

Furthermore, suffice to say that the resulting list of the terminological items proposed and the details related to each item are planned to be submitted to Farhangestan/Cultural Institution of Persian Language and Literature's Council of Lexical Selection and other related unofficial institutes. This way, it can be said that such a translational-cum-terminographic approach in its ultimate phase will endeavor to issue a call for more collaboration to be fostered between subjectfield institutional bodies and translating researchers. 


\subsection{Limitations}

Though the emphasis given in this study is on the necessity of resorting to terminographic work in the process of technical translation, one major limitation imposed on this study is that not every translator, due to the restricting constraints of the work environment or needed aptitude, has enough time and capacity to give to terminographic work as such. Moreover, the final terminographical items proposed might be suggestive of a certain degree of subjectivity being contained in their construction, what might diminish their acceptability in the eyes of the end-users as such. In addition, the terminographic proposals probably might bear and breed a sense of unfamiliarity in the target end-users. Consequently, the translationally-sustained terminographic work may face some limitation in terms of whether the items proposed might gain the common currency within the target discourse and among the ultimate discourse-users. This fact in itself will make communicative demands on the specialized discourse community using the ultimate terminographic items, at least in the initial phases of their proposition. Furthermore, this state of probable unwelcomeness might discourage a translator of specialized discourse from turning to adopt such a strategic approach in making up for the terminographic gaps, and might make him/her turn to using less initiative alternatives such as terminological borrowing, paraphrasing, etc.

\section{Conclusion}

An alternative perspective to address the challenge of probable terminographic gaps which might exist within any specialized discourse can be offered by adopting a translational approach. Putting it another way, translating a text can provide the authorities with a practically authentic path as to how and where to detect the probable terminological gaps in the target specialized discourse. To investigate this claim, the present study tried to conduct an experiment in which the goal of discourse-oriented terminographic work is carried out via EnglishPersian translation. The justification behind this practical venture brings into horizon a course of action which fosters a more cooperative initiative between translation and terminography as two distinct yet interrelated disciplines. This frame of reference in itself will pave the ground for a posture of reciprocity to take shape between the two disciplines as regards the discoursal field of Persian lexical database(s). Therefore, it must be said that the locus of attention in this study is to develop a more workable solution for filling the translationally-detected terminographic gaps. The credence for such a strategic solution, in theoretical terms, lies in going beyond a mere cross-lexical approach towards adopting a cross-textual method that is augmented by a discourse-oriented outlook in translation. The ultimate output of applying such a reciprocation method will be, and in this particular case has been, an ultimate list of terminographical proposals for the special subfield under translation. This is to keep up with the final goal 
expressed in Ricoeur's (2006: 37) statement that: 'In the end [,] the construction of the comparable expresses itself in the construction of a glossary.' Therefore, the end-result of applying such an ad-hoc method for construction of translation equivalents will be the proposition of certain terminological items in the related subfield, however small in scale it turns to be. With regard to the resulting list of terminographic gaps in the case under study, what appears to be notable is the high frequency of noun or nominal form over other lexical forms. This point in itself appears to give credence to Cabré's (2010) statement regarding the prototypicality of terms of nominal category with regard to the referential value. For such a practical outcome to find solid grounds in translational and linguistic studies, the equivalence issues of morphological correspondence and technical suggestivity were underlined, each of which are to be met as best as possible in proposing any terminological item, while taking into account the lexico-semantic potentials of the target language. In turn, the overall results of the approach adopted in the present study might hold practical bearings and confirmatory implications for the prospective affiliation of the two theoretical notions of 'constructing comparables' (Ricoeur, 2006) and 'ad-hoc searches' (Cabré, 1999), proposed in translation and terminography respectively. This way the ad-hoc construction of terminological comparables is seen as a probable subsequent stage to the translation process in trying to provide for the un-provided target terminology. Prospectively, though the performance of such a role in the present study has been examined at micro-discourse level, the significance of its effect can be hypothesized to acquire wider dimensions for such prospective macroscale projects as specialized dictionary compilations and other related material development plans.

\section{References}

Augustyn, Rafal. 2013. Discourse-driven Meaning Construction in Neo-semantic Noun-to-verb Conversions [Meaning Construction in Noun-to-verb Conversions]. Research in Language 11(2). 141-161.

Burkhanov, Igor. 1998. Lexicography: A Dictionary of Basic Terminology. Rzeszów: Wydawnictwo Wyższej Szkoly Pedagogicznej.

Cabré, Maria Teresa. 1999. Terminology: Theory, Methods and Application. In: Janet Ann DeCesaris (trans.), Juan C. Sager (ed.), Amsterdam and Philadelphia: John Benjamins Publishing Company.

Cabré, Maria Teresa. 2010. Terminology and Translation. In: Yves Gambier and Luc van Doorslaer (eds.), Handbook of Translation Studies, 356-366. Amsterdam and Philadelphia: John Benjamins Publishing Company.

Catford, John Cunnison. 1965. A Linguistic Theory of Translation. Oxford: Oxford University Press.

Fellbaum, Christiane. 1998. A Semantic Network of English: The Mother of All WordNets. Computers and the Humanities 32. 209-220.

Haddad-e Adel, Golam-Ali. 2008. Lexical Selection and Out-sourcing. Name-ye Farhangestan $38(1 / 2) \cdot 2-4$. 
Basil Hatim and Jeremy Munday. 2004. Translation: An Advanced Resource Book. London and New York: Routledge.

Hartmann, Reinhard Rudolf Karl. 2007. Interlingual Lexicography Selected Essays on Translation Equivalence, Contrastive Linguistics and the Bilingual Dictionary. Tübingen: Max Niemeyer Verlag.

Johnson, Gerald J. 1992.Talking about Computers: From Metaphor to Jargon. AI and Society, 6(3). 263-270.

Kaafi, Ali. 1995. Scientific Principles of Word Selection and Word Formation. Name-ye Farhangestan 2(1/2). 49-67.

Mansuri, Ahmad. 2003. On the Technology of Massive Word-selection in Word-selection Industry. Name-ye Farhangestan 22(2/6). 179-191.

Abbas Mehrpooya and Negar Nowroozzadeh. 2013a. Metaphor-laced Language of Computer Science and Receptor Community Users. Journal of Technical Writing and Communication 43(4). 399-419.

Montgomery, Scott L. 2010. Scientific translation. In: Yves Gambier and Luc van Doorslaer (eds.), Handbook of Translation Studies, 356-366. Amsterdam and Philadelphia: John Benjamins Publishing Company.

Nematzadeh, Shahin. 2000. Reasoning in Lexical Selection. Name-ye Farhangestan 16(4/4). 128-134.

Ricoeur, Paul. 2006. On Translation. Eileen Brennan (trans.), With an introduction by Richard Kearney. London and New York: Routledge.

Sadeghi, Ali-Ashraf. 1991. Ways and Possibilities of Word Formation in Contemporary Persian Language. Danesh Publishing 64. 256-262.

Schäffner, Christina. 2004. Metaphor and Translation: Some Implications of a Cognitive Approach. Journal of Pragmatics 36. 1253-1269.

Yamin, Muhammad Hossein. 2004. A Glance at Word-selection Strategies in Dari Persian Language. Name-ye Farhangestan 24(4/6). 159-162. 